\title{
Removal Of Color and Chemical Oxygen Demand From Textile Wastewater Using Advanced Oxydation Process (AOPs)
}

\author{
Qomarudin Helmy ${ }^{1,2, *}$, Suprihanto Notodarmojo ${ }^{1}$, Indah A. Aruan ${ }^{3}$, and Rizki Apriliawati ${ }^{3}$ \\ ${ }^{I}$ Water and Wastewater Engineering Research Group, Institut Teknologi Bandung \\ ${ }^{2}$ Bioscience and Biotechnology Research Center, Institut Teknologi Bandung \\ ${ }^{3}$ Environmental Engineering Department, Faculty of Civil and Environmental Engineering, Institut Teknologi \\ Bandung, Ganesha No. 10, Bandung, West Java, Indonesia \\ *corresponding author: helmy@tl.itb.ac.id
}

\begin{abstract}
Large quantities of dyes used in the textile industry are lost to the effluents and flows into surface water during the manufacturing and processing operations. Many methods have been used such as biological, physical and chemical treatment of dye containing wastewater. Among these treatment technique, activated sludge, flocculation, and adsorption are the most commonly applied methods in Indonesia. Dyes are usually resistant to aerobic degradation, for example decolorization of azo dyes has been found to be less effective solely using this treatment. On the other hand, flocculation and adsorption methods are not destructive, mainly just concentrate and separate the pollutants phases. This research paper investigates the removal of color and chemical oxygen demand/COD from textile wastewater using advanced oxydation process either by ozone-UV and zinc oxide photocatalyst. Effects of various variables on decolorization and COD removal process have been investigated. The results showed that ozone/UV could achived a complete decolorization (100\% removal) when $40 \mathrm{mg} / \mathrm{l}$ dye initial concentration was treated with $170.43 \mathrm{ppm} / \mathrm{min}$ ozonation for $120 \mathrm{~min}$ of incubation period. The same color removal efficiency also achieved when $20 \mathrm{mg} / \mathrm{l}$ dye initial concentration treated in the photocatalytic reactor contained $0.71 \mathrm{mg} / \mathrm{cm}^{2}$ of $\mathrm{ZnO}$ nanoparticle after $135 \mathrm{~min}$ of incubation period. COD removal efficiency for ozone/UV and $\mathrm{ZnO}$ photocatalytic treatment was $60 \%$ and $77 \%$, respectively.
\end{abstract}

Keywords-Ozonation, Photocatalytic, Decolorization, Dye, ZnO.

\section{INTRODUCTION}

$\mathrm{T}$ extile industries use many kinds of artificial composite dye and discharge large amounts of highly colored wastewater. This wastewater must be treated prior to discharge in order to comply with the environmental protection laws for the receiving waters [1]. The presence of color in water and wastewater, even a small amount, is highly visible and affects the aesthetic value. Color is often caused by organic matter. Forms of organic content that cause color pollution includes synthetic chemical dyes, and natural dissolved organics such as lignin and tannins. High levels of color in wastewater have an impact on photosynthesis activity by reducing the penetration of sunlight to lower levels in the water body affecting aquatic life. Standards exist to provide guidance on the safe level of color that can be discharged to the environment e.g. in the European Economic Community Standard. Unfortunately, Indonesian government standard for textile wastewater for color parameter is not regulated so far (The Indonesian Ministry of Environment and Forestry Decree No. 5 Year 2014) [2].

Majority of the color removal techniques work either by concentrating the color into sludge, or by partial breakdown or complete breakdown of color molecule. Synthetic dyes, such as azo dyes, are resistant to microbial degradation under the aerobic conditions, because synthetic dyes are designed to be resistant to chemical fading and light induced oxidative fading.
Other factors involved in reducing the biodegradation of dyes include high water solubility and high molecular weight, which inhibit permeation through biological cell membrane. Basic dyes are removed from wastewaters by adsorption on to activated sludge. Acid dyes and reactive dyes, however, exhibit low adsorption values and thus pass through activated sludge processes unaffected. Aerobic systems have difficulties in removing many dyestuffs and may be subject to mechanical breakdown, expensive capital and running costs, susceptibility to shock loading, occupation of large areas of land and production of large quantity of sludge. To meet a safe level of discharge to the environment, industries have to implement on-site treatment. Biological treatment processes are frequently used to treat textile effluents. However, color is not readily removed from microbialbased treatment processes. Therefore, due to environmental implications and limitations of each of the above treatment methods, research on combining one of the biological treatment methods with other techniques such as advanced oxidation processes (AOP) is needed to ensure a cost-effective and best approach technology for hard-to-treat dyes/chemicals pollution treatment and control [3]. Recent developments of AOP, have led to new improvements of the oxidative degradation of the organic compounds. UV irradiation in the presence of $\mathrm{H}_{2} \mathrm{O}_{2}$ has yielded encouraging results of color removal from azo-reactive dye containing waters $[4,5,6,7]$.

The use of AOP for heavily (less/low)-biodegradable components in wastewater is important because AOPs can degrade complex chemical structures to more easily degradable molecules, which can then be treated in a 
conventional and less expensive way, e.g. conventional oxidation of activated sludge process. The goal of any AOPs method is to generate and use hydroxyl free radical $(\mathrm{OH} \bullet)$ as strong oxidant to destroy compound that can not be oxidized by conventional oxidant. Advanced oxidation processes are characterized by production of $\mathrm{OH} \cdot$ radicals and selectivity of attack which is a useful attribute for an oxidant [8].

The aim of the present study was to test different combinations of AOPs for treatment of synthetic textile dye (remazol brilliant blue) to establish the most efficient for color and COD removal. After this is achieved, further work on biological treatment will be applied to increase the treated wastewater quality for reuse in textile industry.

\section{METHOD}

\section{A. Materials}

Remazol Brilliant Blue (RB-B) dye was obtained from environmental laboratory, Indonesian center for textile, Bandung. Zinc Acetate Dehydrate purchased from Merck. Generic Ozone generator (X-Troy) with
$\mathrm{O}_{3}$ output of $400 \mathrm{mg} /$ hour. 15 watts UV-C lamp (Philips TUV G15T8).

\section{B. Apparatus}

The laboratory-scale photoreactor was designed in cylindrical shaped with $72 \mathrm{~cm}$ height and outer diameter of $16 \mathrm{~cm}$. Inside the reactor, a quartz tube containing UV-C lamp predominantly emit at $254 \mathrm{~nm}$ (15W, Philips TUV G15T8) positioned in the center of reactor to ensure homogenous radiation field inside the reactor. Schematic representation of ozoneUV reactor setup is shown in Figure 1, while Rotating Photocatalytic Contactor (RPC) using $\mathrm{ZnO}$ catalyst is shown in Figure 2. Zinc oxide was supported on each plate, and the plate/discs are rotated. 2 UV lamps (15W, Philips TUV G15T8), emitted power per lamp: $4.9 \mathrm{~W}, \lambda \max =254 \mathrm{~nm}$ ) irradiate the catalyst surface. 9 pieces of discs with diameter of $10 \mathrm{~cm}$ are arranged in series with distance between disc of $5 \mathrm{~cm}$. Thickness of discs is $0.2 \mathrm{~mm}$, measured catalyst coated area is $1398 \mathrm{~cm}^{2}$ with $\mathrm{ZnO}$ concentration of $0.71 \mathrm{mg} / \mathrm{cm}^{2}$.

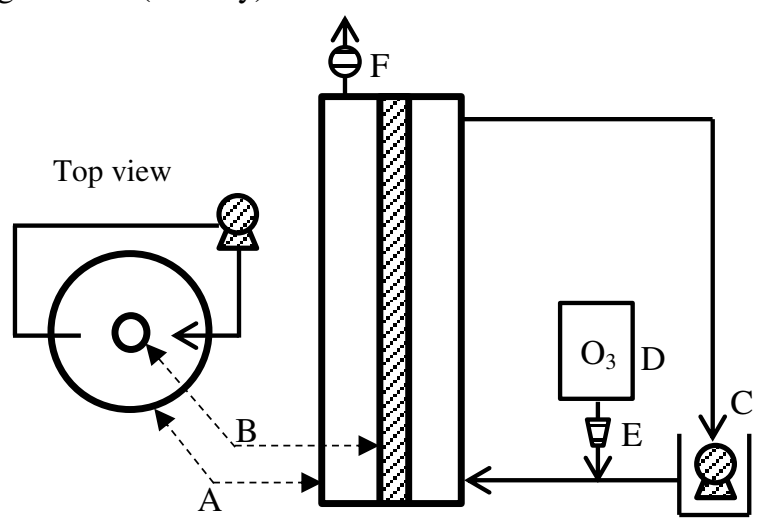

Figure 1. Experimental setup in the AOPs (Ozone-UV) reactor: A) PVC tube, B) UV-C lamp, C) recirculating pump, D) ozone generator, E) flowmeter, F) excess ozone absorber.

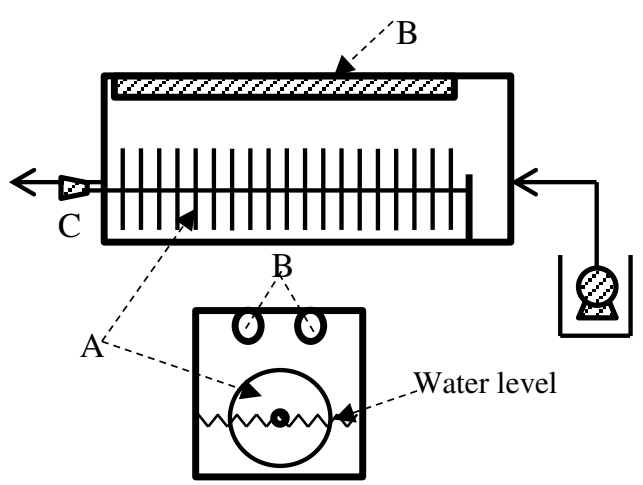

Side view

Figure 2. Experimental setup in the AOPs (rotating $\mathrm{ZnO}$ photocatalytic contactor): A) rotating disc with $\mathrm{ZnO}$ attached, B) UV-C lamp, C) rotating motor.

\section{Experimental procedure and analysis}

The advanced oxidation processes experiments were carried out with 2 different AOPs reactor. First reactor was equipped with ozone-UV irradiation. The volume of bench scale reactor is $8 \mathrm{~L} . \mathrm{O}_{3}$ is produced from dried air with maximum $\mathrm{O}_{3}$ production of 400 $\mathrm{mg} / \mathrm{h}$ and flow rate of the gas stream 2 LPM. $\mathrm{O}_{3}$ was introduced in the system via venturi injector, diffuses into the water and reacts with the substances in the water. $\mathrm{O}_{3}$ concentration is measured with $\mathrm{O}_{3}$ analyser (KRK Ozone Meter, $\mathrm{O}_{3}-2 \mathrm{Z}$ ) in certain incubation time (figure 1). Consequently the system was operating in a batch mode with the water being complete mixed.

Second reactor was equipped with serial disc coated with $\mathrm{ZnO}$ particle. Figure 2 shows a schematic of the rotating photocatalytic contactor (RPC) used in this 
study. $\mathrm{ZnO}$ was coated on discs using the procedure outlined below, and the discs are rotated. On top of the discs, 2 UV lamps (2 x Phillips TUV G15T8, UVC emitted per lamp: $4.9 \mathrm{~W}, \lambda \max =254 \mathrm{~nm}$ ) irradiate the catalyst surface. On rotation, a thin film of liquid becomes entrained on the disc from the bulk solution. Illumination and hence reaction takes place in the headspace. Variation of the rotation speed of the discs was accomplished by the application of a variable voltage of a DC motor fitted with a gearbox.

Catalyst preparation refer to Kayani et al. [9], whereas a sol gel method was used to prepare $\mathrm{ZnO}$ thin films. Zinc acetate dihydrate, ethanol and distilled water were used as a starting material, solvent and stabilizer, respectively. $0.5 \mathrm{M}$ solution was prepared by dissolving $1 \mathrm{~g}$ of zinc acetate dehydrate in $10 \mathrm{~mL}$ of absolute ethanol, after which the solution was stirred vigorously using a magnetic stirrer for 1 hour on a hot plate at $60^{\circ} \mathrm{C}$. Initially the solution was milky but after stirring for approximately 20 minutes the solution became homogeneous, transparent and stable. After stirring for about 1 hour the solution was allowed to cool, and $10 \mathrm{~mL}$ of water was added, drop by drop into the solution, and again the solution was stirred continuously for 3 hours at $100^{\circ} \mathrm{C}$. The sol was aged for 24 hours and then dip-coating was carried out. Thin films of $\mathrm{ZnO}$ were deposited at withdrawal speed of 100-200 mm/s. Each layer of as prepared films was dried at $80{ }^{\circ} \mathrm{C}$ in air for 15 minutes. The dipping process was conducted 3 times after each layer cooling down to room temperature. Finally, all the films were calcined at $350^{\circ} \mathrm{C}$ for 1 hour to remove organic matters from the films (figure 3 ).

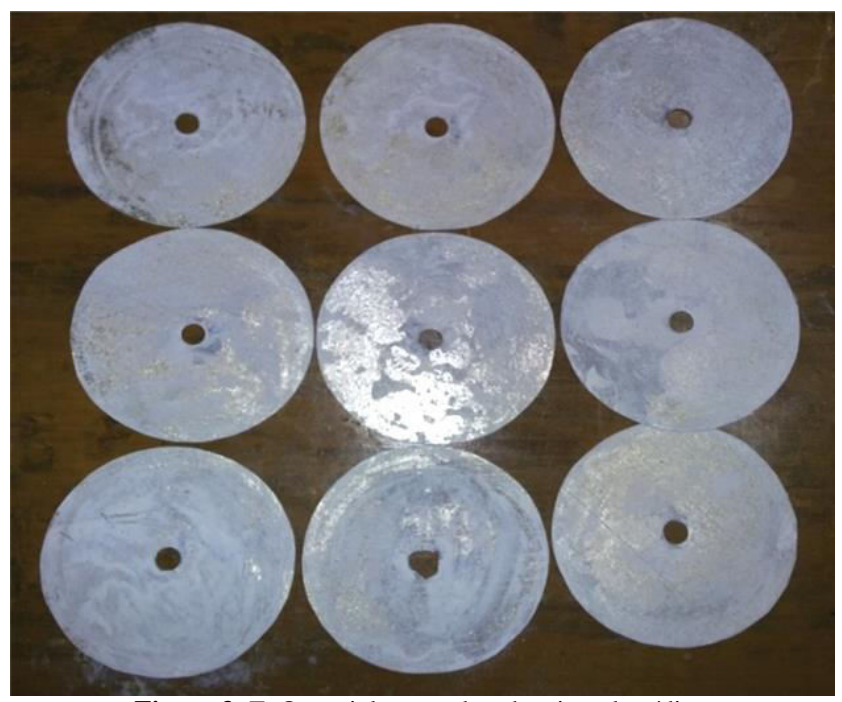

Figure 3. $\mathrm{ZnO}$ particle coated to the zinc plate/disc.

RB-B initial concentration used in this study was 5; $10 ; 20 \mathrm{ppm}$ ( $\mathrm{ZnO}$ photocatalytic) and 10; $40 \mathrm{ppm}$ (Ozonation), respectively. During the AOPs experiments, a $10 \mathrm{~mL}$ sample was taken from the circulation loop in the batch system at regular time intervals for COD and color measurements according to the standard methods for the examination of water and wastewater [10].

\section{RESULTS AND DISCUSSION}

\section{A. AOP experiments - color removal}

Advanced oxidation processes are characterized by production of $\mathrm{OH} \bullet$ radicals and selectivity of attack which is a useful attribute for an oxidant. The versatility of AOP is also enhanced by the fact that they offer different possible ways for $\mathrm{OH} \bullet$ radicals. Ozone is a powerful oxidant agent for water and wastewater. Once dissolved in water, ozone reacts with a great number of organic compounds in two different ways: by direct oxidation as molecular ozone or by indirect reaction through formation of secondary oxidants like $\mathrm{OH} \bullet$ radicals $[8,11,12]$.

The highest color reduction was found in the reactor with combination of $\mathrm{O}_{3}+\mathrm{UV}$ (figure 4-8) with the reduction of color by $100 \%$ for both initial concentration of $10 \mathrm{ppm}$ and $40 \mathrm{ppm}$ RB-B, respectively (both achieved at $60 \mathrm{~min}$ incubation time). The treatments of textile dye $\mathrm{RB}-\mathrm{B}$ with $\mathrm{O}_{3}$ alone (figure 4, 7) were less effective compared with combinations of $\mathrm{O}_{3}+\mathrm{UV}$ (figure 5, 8) for color removal. Photolisis of UV light give a contribution up to $27 \%$ decoloration of RB-B alone. Increasing in ozone concentration make the decoloration of RB-B dye became faster up to 1.3-1.5 times. 


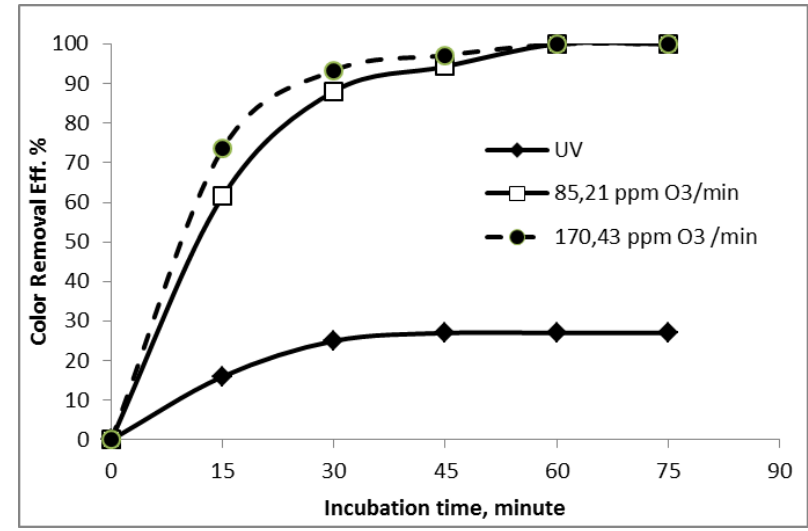

Figure 4. Color removal efficiency of $10 \mathrm{ppm}$ initial concentration of RB-B as the fuction of the AOPs $\left(\mathrm{O}_{3}\right)$ duration.

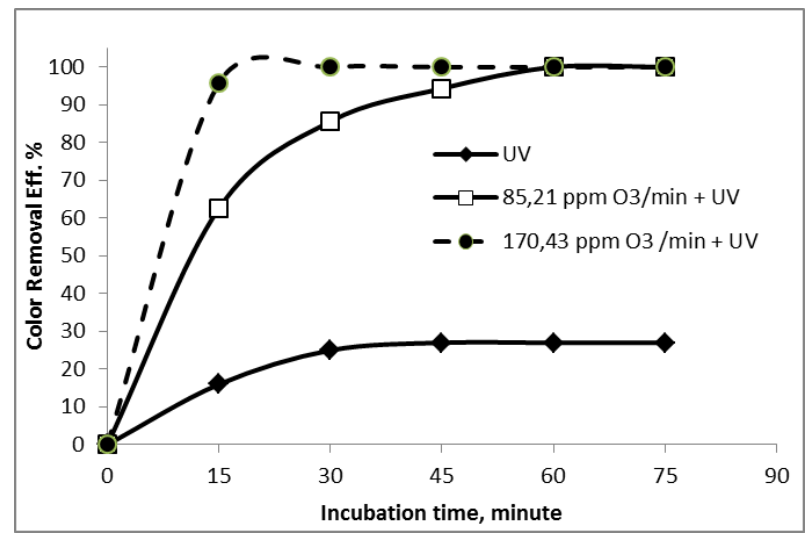

Figure 5. Color removal efficiency of $10 \mathrm{ppm}$ initial concentration of RB-B as the fuction of the AOPs $\left(\mathrm{O}_{3}+\mathrm{UV}\right)$ duration.

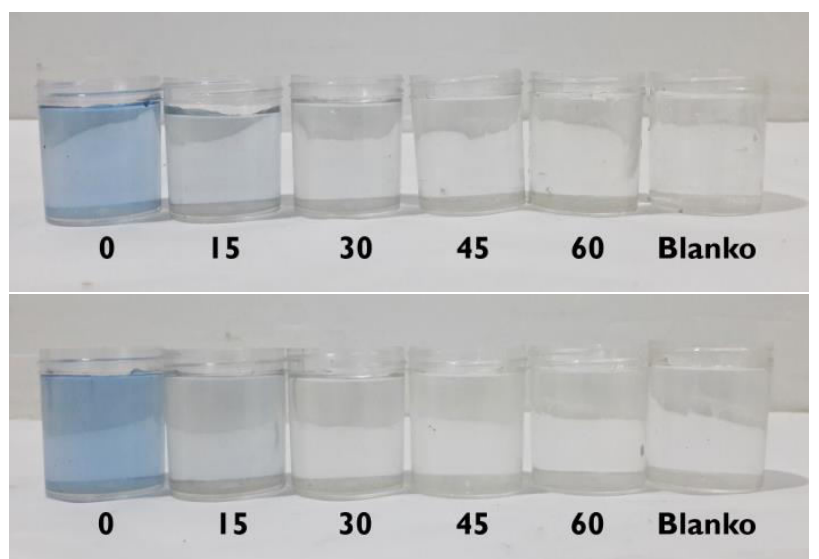

Figure 6. Visual image of color gradation of $10 \mathrm{ppm}$ RB-B initial concentration as the function of the AOPs duration (upper: $\mathrm{O}_{3}$, lower: $\mathrm{O}_{3}+\mathrm{UV}$ ).

Figures 6, 9 shows the visual image of color gradation along with incubation time period of ozonation process. Many studies indicated that color and organics removal efficiencies are mainly dependent on dye/organic matter contents, $\mathrm{pH}$, temperature, and $\mathrm{O}_{3}$ transfer to the wastewater $[3,13,14]$.

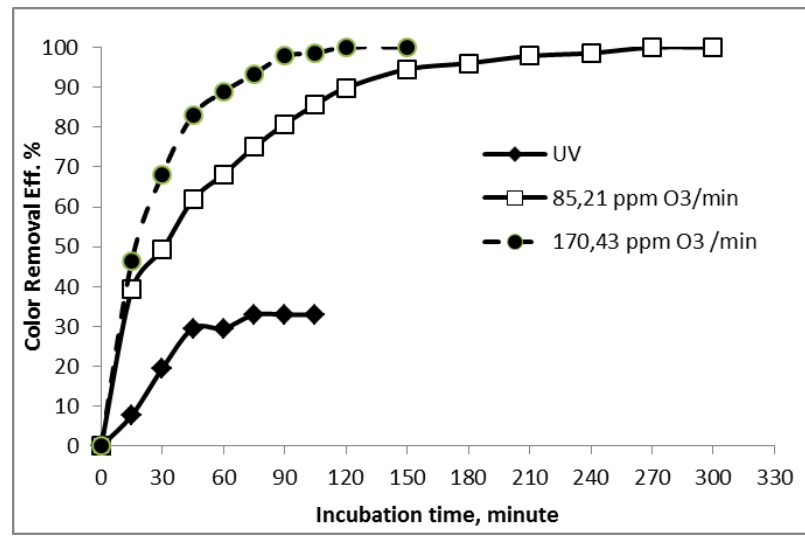


Figure 7. Color removal efficiency of $40 \mathrm{ppm}$ initial concentration of RB-B as the fuction of the AOPs $\left(\mathrm{O}_{3}\right)$ duration.

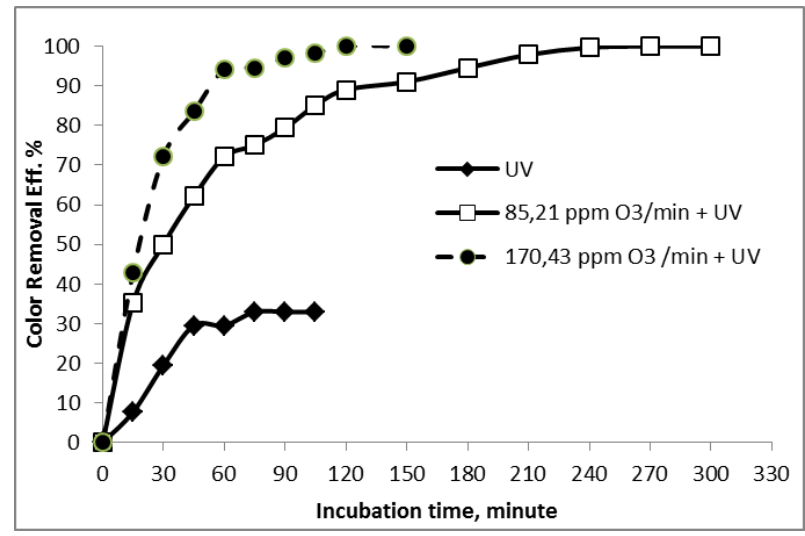

Figure 8. Color removal efficiency of $40 \mathrm{ppm}$ initial concentration of RB-B as the function of the AOPs $\left(\mathrm{O}_{3}+\mathrm{UV}\right)$ duration
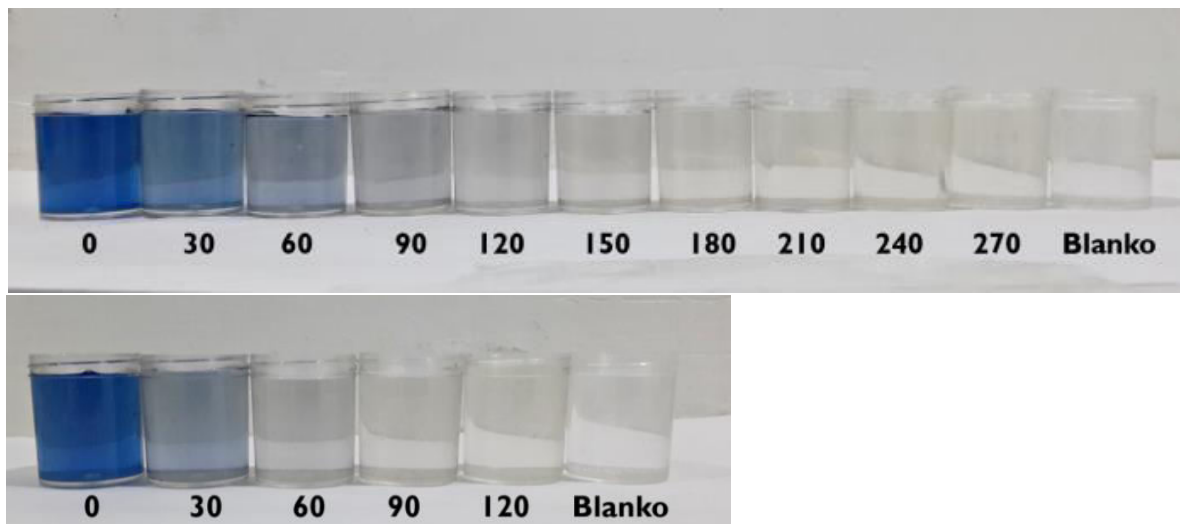

Figure 9. Visual image of color gradation of $40 \mathrm{ppm}$ RB-B initial concentration as the function of the AOPs duration (upper: $\mathrm{O}_{3}$, lower: $\mathrm{O}_{3}+\mathrm{UV}$ ).

In the ozonation, the limiting factor in decolorization rate is the interface between gas and liquid and that a packed column gives more efficient use of ozone due to improved contact. It was shown that the color removal increases as dwell time increases. The ozone concentration is an important parameter to adjust and control the decolorization of dyes in the $\mathrm{O}_{3} / \mathrm{UV}$ reactor. Degradation of the color is due to the hydroxyl radicals generated upon photolysis of ozone. Several studies have proposed different reaction mechanisms for this photolysis. It is widely accepted that the main interaction between $\mathrm{O}_{3}$ with UV irradiation and free radicals are well represented by the following reactions $[11,15]$.

$$
\begin{aligned}
& \mathrm{O}_{3}+\mathrm{H}_{2} \mathrm{O} \rightarrow \mathrm{HO}_{3}+\mathrm{OH} \bullet \\
& \mathrm{HO}_{3} \rightarrow \mathrm{O}_{3} \bullet+\mathrm{H}^{+} \\
& \mathrm{HO}_{3} \leftarrow \rightarrow \mathrm{OH} \bullet+\mathrm{O}_{2}
\end{aligned}
$$

In photocatalytic experiments, RB-B dye with a volume of 2 liter was fed to the RPC. The disc was rotated at $25 \mathrm{rpm}$ for certain time and subsequently drawn for sample analysis. The decolorization of the dyes was studied under different conditions: under UV without photocatalyst; under $\mathrm{ZnO}$ photocatalyst; and under $\mathrm{UV} / \mathrm{ZnO}$ photocatalyst. All the reactions were carried out at $\mathrm{pH}=7$. In the case of the decolorization of the dyes studied under UV without photocatalyst, almost $80 \%$ decoloration was achieved with initial concentration of $5 \mathrm{ppm}$ of RB-B. This indicated that UV-C irradiation have a strong photolysis capabilitiy effect on a thin layer of RB-B dye, whereas under the Zno photocatalyst without UV irradiation give lower decoloration effect $(60 \%)$. Complete decoloration (100\% removal) of $5 \mathrm{ppm}$ $\mathrm{RB}-\mathrm{B}$ was achieved under the $\mathrm{ZnO}+\mathrm{UV}$ irradiation condition after $90 \mathrm{~min}$ incubation time (figure 10).

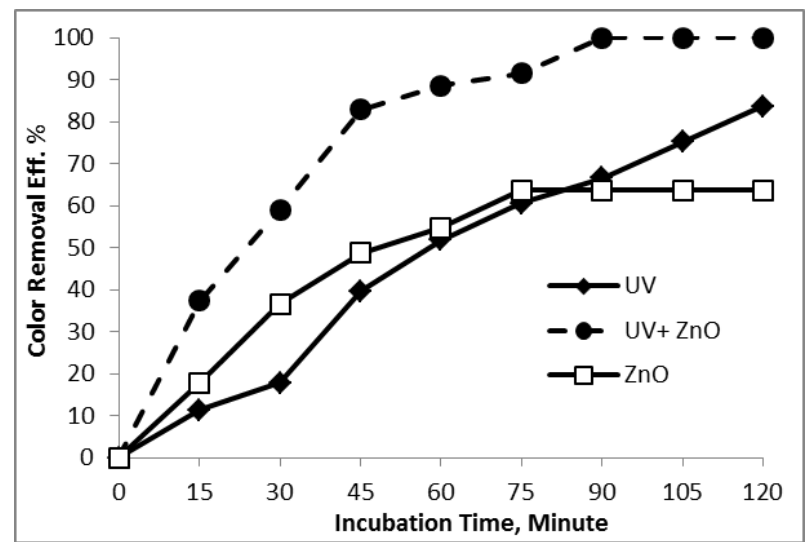


Figure 10. Color removal efficiency of $5 \mathrm{ppm}$ initial concentration of RB-B as the fuction of the AOPs duration (RPC with 25 rpm rotating disc; $\left.0.71 \mathrm{mg} \mathrm{ZnO} / \mathrm{cm}^{2}+\mathrm{UV}\right)$.

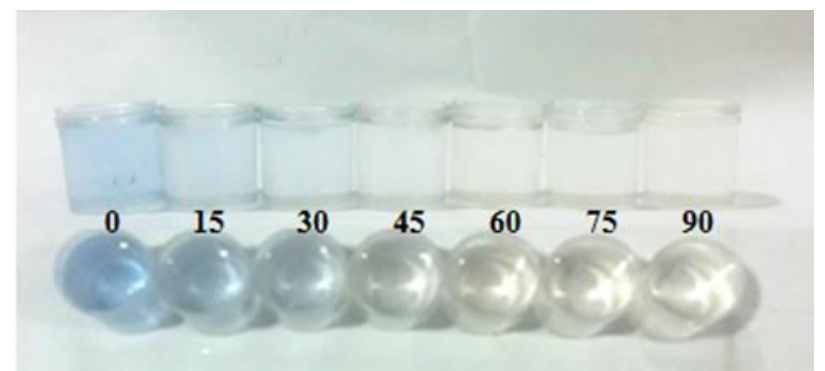

Figure 11. Visual image of color gradation of $5 \mathrm{ppm}$ RB-B initial concentration as the function of the AOPs duration (RPC with 25 rpm rotating disc; $\left.0.71 \mathrm{mg} \mathrm{ZnO} / \mathrm{cm}^{2}+\mathrm{UV}\right)$.

The decoloration of RB-B was found to slightly decrease with an increase in the initial dye concentration (figure 12). The active surface on the catalyst available for reaction is very crucial for the degradation to take place, but as the dye concentration is increased and the catalyst amount is kept constant, results in fewer active sites for the reaction. With increased dye molecules the solution became more intense coloured and the path length of photons entering the solution decreased thereby only fewer photons reached the catalyst surface. And therefore, the production of hydroxyl and superoxide radicals were limited [16].

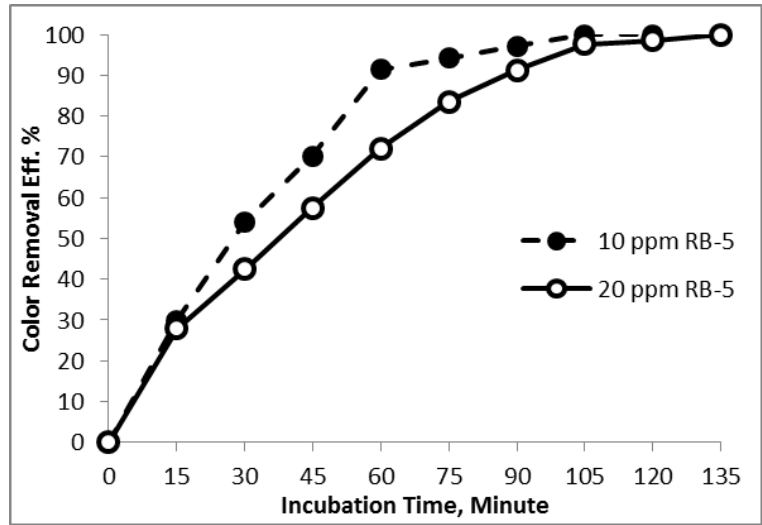

Figure 12. Color removal efficiency of 10;20 ppm initial concentration of RB-B as the fuction of the AOPs duration (RPC with 25 rpm rotating disc; $0.71 \mathrm{mg} \mathrm{ZnO} / \mathrm{cm}^{2}+\mathrm{UV}$ ).

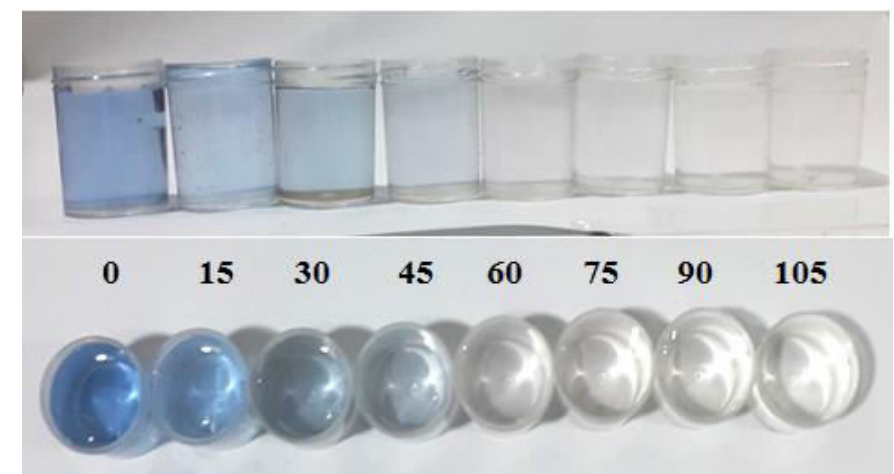

Figure 13. Visual image of color gradation of $10 \mathrm{ppm}$ RB-B initial concentration as the function of the AOPs duration (RPC with 25 rpm rotating disc; $0.71 \mathrm{mg} \mathrm{ZnO} / \mathrm{cm}^{2}+\mathrm{UV}$ )

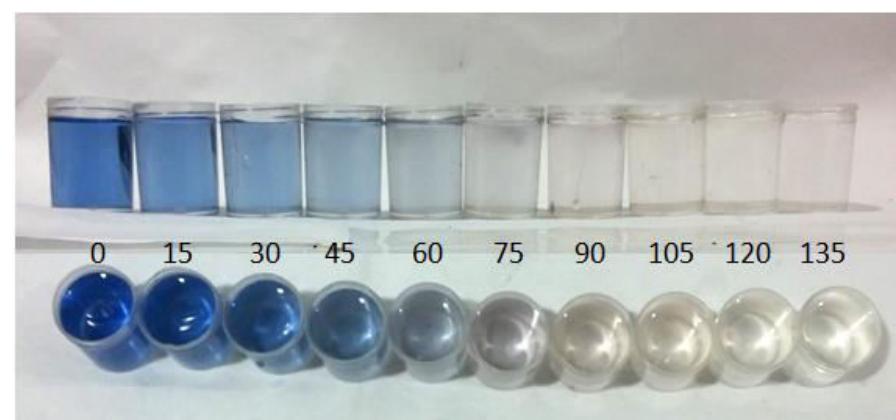

Figure 14. Visual image of color gradation of $20 \mathrm{ppm}$ RB-B initial concentration as the function of the AOPs duration (RPC with 25 rpm rotating

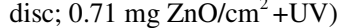


The experimental results showed that with $\mathrm{ZnO} / \mathrm{UV}$, for the first 60 minutes the color removal efficiency was higher relative to the subsequent (last) 60 minutes. The contributing factors to the overall photocatalytic efficiency for $\mathrm{RB}-\mathrm{B}$ decoloration is $\mathrm{OH} \bullet$ production. The powerful oxidizing hydroxyl radicals react with the dye molecules resulting in the destruction of their intrinsic color.

$\mathrm{RX}+\mathrm{OH} \bullet \rightarrow$ products

$\mathrm{RX}+\mathrm{O}_{2} \mathrm{H} \bullet \rightarrow$ products

The $\mathrm{OH} \bullet$ radicals are capable of oxidizing organic compounds mostly by hydrogen abstraction $[17,18]$.

$\mathrm{ZnO}+h \gamma \rightarrow \mathrm{ZnO}^{*}$

$\mathrm{ZnO}^{*}+\mathrm{H}_{2} \mathrm{O} \rightarrow \mathrm{ZnO}^{*}+\mathrm{H}_{+}+\mathrm{OH} \bullet$

$\mathrm{OH} \bullet+$ dye molecule $\rightarrow$ intermediates $\rightarrow \mathrm{CO}_{2} \uparrow+$

$\mathrm{H}_{2} \mathrm{O}+$ mineral salts

This reaction generates organic radicals which by addition of molecular oxygen yield peroxyl radical. These intermediates initiate thermal chain reactions of oxidative degradation leading finally to carbon dioxide, water and mineral salts. Electrophilic addition of $\mathrm{OH} \cdot$ radicals to organic compounds constitutes another mechanism of oxidative degradation $[18,19,20]$.

\section{B. AOP experiments - COD removal}

Chemical oxygen demand is a common used parameter for the characterization of organic matter present in textile wastewaters; it depends on the dyes used in the production process. COD removal was observed in all AOP treatment cases. After 75 min of AOP treatments, COD reduction observed from $23.8 \%$ to $30.7 \%$ (5 ppm RB-B initial concentration in $\mathrm{O}_{3}+\mathrm{UV}$ system) was achieved. COD reduction between AOP combinations applied by increasing $\mathrm{O}_{3}$ dose from $85.2 \mathrm{ppm}$ to 170.4 ppm were not significant (from $57.1 \%$ to $60 \%$, after 120 min incubation time) indicating that organics breakdown still in the form of intermediate products (figures 15).

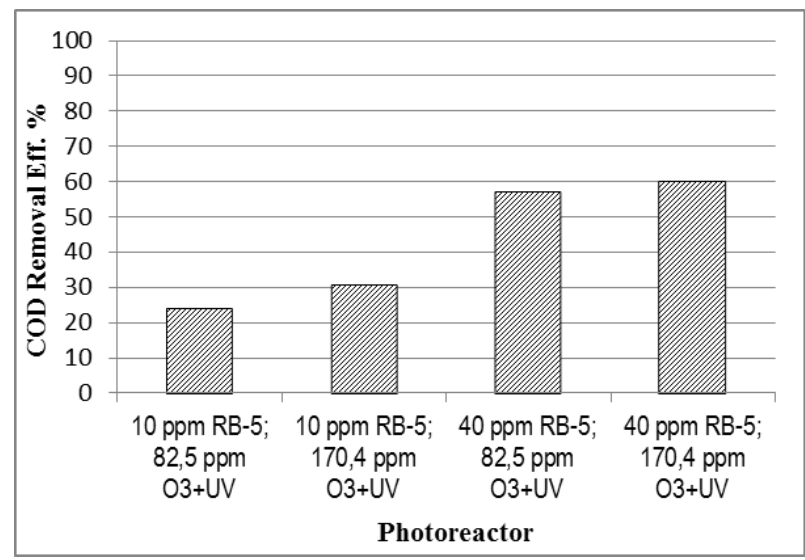

Figure 15. COD removal efficiency for $\mathrm{O}_{3}+\mathrm{UV}$ system.

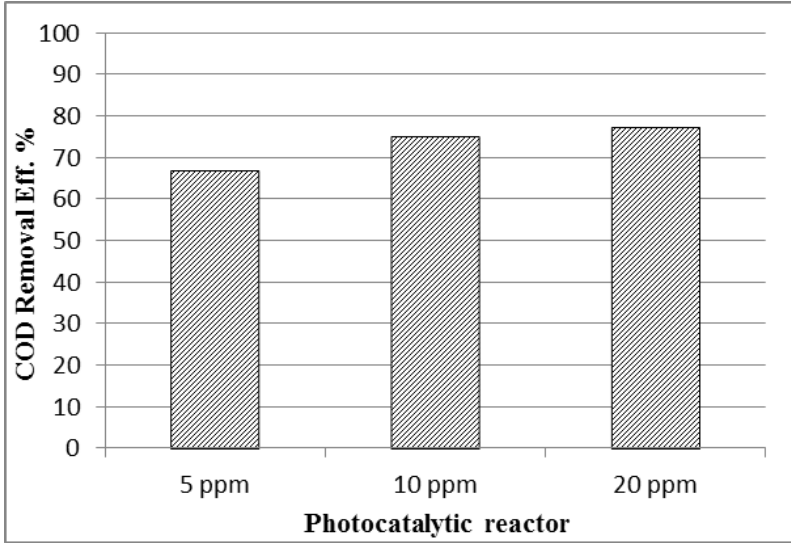

Figure 16. COD removal efficiency for RPC with $25 \mathrm{rpm}$ rotating disc; $0.71 \mathrm{mg} \mathrm{ZnO/ \textrm {cm } ^ { 2 }}+\mathrm{UV}$ system

A significant COD removal was observed in the RPC system, whereas $66.6 ; 75$; and $77.2 \%$ removal efficiency achieved when 5; 10; and $20 \mathrm{ppm}$ of initial RB-B concentration was fed to the system, respectively (figure 16). The results demonstrate that RPC system with $\mathrm{ZnO}$ catalyst exhibits high photocatalytic activity not only in the decolorization but also in mineralization of colorless organic pollutants (shown by decreasing concentration in both color and COD). Conversely result shown in the ozonation reactor, where complete decoloration is not linier with organic removal efficiency. In the ozonation, rate of contact between gas and liquid interface became limiting factor in the oxidation process.

\section{CONCLUSION}

The presented lab-scale AOP treatment of RB-B dye was designed to evaluate treatment efficiencies of different AOP combinations for color and COD removal. The results indicated that all AOP combination shows a promising efficiency in removing both color and COD. The most efficient color removal was achieved in the ozonation reactor (combination of $\mathrm{O}_{3}$ treatment $+\mathrm{UV}$ irradiation) with the average efficiencies of color removal of $100 \%$ after $120 \mathrm{~min}$ of water recirculation in the batch reactor system. 
Since AOP system represents a significant cost, instead of ultimate degradation to complete mineralisation of organic compounds, a partial breakdown to more readily biodegradable compounds is more preferable. After partial oxidation by AOP, microorganisms can be used in a post-treatment process for complete mineralization of pollutants in the wastewater. Therefore, the use of chemical oxidation combined with biological degradation process may provide more economical and effective process than AOP or biodegradation alone. In the presented study, organic matter were not completely destroyed during the AOP treatments used, thus a posttreatment with biological process degradation is strongly advised.

\section{AKNOWLEDGEMENTS}

The study was performed within the ITB-P3MI research scheme; a research programs on community service, and innovation of ITB research group which is co-funded by the Indonesian Ministry of Research, Technology and Higher Education (Ristek-Dikti).

\section{REFERENCES}

[1] V.S. Ashtekar, V.M. Bhandari, S.R. Shirsath, P.L.V.N. Sai Chandra, P.D.Jolhe and S.A.Ghodke, Dye Wastewater Treatment: Removal of Reactive Dyes Using Inorganic and Organic Coagulants, Journal of Industrial Pollution Control, vol. 30, pp. $33-42,2014$

[2] The Indonesian Ministry of Environment and Forestry, Wastewater effluent standard for industries, Decree No. 5, 2014.

[3] A. K. Klemencic, M. Krzyk, D. Drev, D. Balabanic, and B. Kompare, Recycling of textile wastewater treated with various cominations of advanced oxidation processes (AOP), Acta hydrotechnica, vol. 25, pp. 31-39, 2012.

[4] Akyol, H.C. Yatmaz, and M. Bayramoglu, Photocatalytic decolorization of Remazol Red RR in aqueous $\mathrm{ZnO}$ suspensions, Applied Catalysis B: Environmental, vol. 54, pp. 19-24, 2004.

[5] Ahmet, Y. Ayfer, L. Doris, N. Nese and K. Antonius, Ozonation of high strength segregated effluents from a woollen textile dyeing and finishing plant, Dyes and Pigments, vol. 58, pp. 93-98, 2003.

[6] S. Lidia, J. Claudia and N.K. Santosh, A comparative study on oxidation of disperse dyes by electrochemical process, ozone, hypochlorite and fenton reagent, Water Research, vol. 35, pp. 21292136, 2001.

[7] L. Stanislaw, S. Monika and Z. Renata, Biodegradation, decolourisation and detoxification of textile wastewater enhanced by advanced oxidation processes, Journal of Biotechnology, vol. 89, pp 175-184, 2001.

[8] A. Al-Kdasi, A. Idris, K. Saed, and C. T. Guan, Treatment of textile wastewater by advanced oxidation processes-a review, Global Nest: the Int. J. Vol 6, pp. 222-230, 2004.

[9] Z. N. Kayani, M. Iqbal, S. Riaz, R. Zia, and S. Naseem, Fabrication and properties of zinc oxide thin film prepared by sol-gel dip coating method, Materials Science-Poland, vol. 33, pp. 515-520, 2015.

[10] APHA-AWWA-WEF, Standard methods for the examination of water and wastewater, 22nd edition, 2012.

[11] Gottschalk, A. Libra, and A. Saupe, "Ozonation of Water and Wastewater: A Practical Guide to Understanding Ozone and its Applications". Weinheim, Wiley-VCH, 2010.

[12] S. Baig and Liechti, Ozone treatment for biorefractory COD removal, Water Science and Technology, vol. 43, pp. 197-204, 2001.

[13] A. Muhammad, A. Shafeeq, M.A. Butt, Z.H. Rizvi, M.A. Chughtai, and S. Rehman, Decolorization and removal of COD and BOD from raw and biotreated textile dye bath effluent through advanced oxidation processes (AOPs), Brazilian Journal of Chemical Engineering, vol. 25, pp. 453-459, 2008.

[14] L. Kos, and J. Perkowski, Decolouration of real textile wastewater with advanced oxidation processes, Fibres and Textiles in East Europe, vol. 11, pp. 81-85, 2003.

[15] R. Andreozzi, V. Caprio, A. Insola, and R. Marotta, Advanced Oxidation Process (AOP) for Water Purification and Recovery, Catalysis Today, vol. 53, pp. 51-59, 1999.

[16] B. Zielinska, J. Grzechulska, and A.W. Morawski, Photocatalytic decomposition of textile dyes on TiO2-Tytanpol A11 and TiO2-Degussa P25, Journal of Photochemistry and Photobiology A: Chemistry, vol. 157 , pp. 65-70, 2003.

[17] K. Byrappa, A.K. Subramani, S. Ananda, K.M.L. Rai, R. Dinesh, and M. Yoshimura, Photocatalytic degradation of rhodamine $\mathrm{B}$ dye using hydrothermally synthesized $\mathrm{ZnO}$, Bull. Mater. Sci., Vol. 29, pp. 433-438, 2006.

[18] H. Amin, A. Amer, A. El-Fecky, and I. Ibrahim, Treatment of textile waste water using H2O2/UV system, Physicochemical Problems of Mineral Processing, vol. 42, pp. 17-28, 2008.

[19] M.S. Mashkour, A.F. Al-Kaim, L.M. Ahmed, and F.H. Hussein, Zinc oxide assisted photocatalytic decolorization of reactive red 2 dye, Int. J. Chem Sci., vol. 9, pp. 969-979, 2011.

[20] R. Saravanan, S. Karthikeyan, V.K. Gupta, G. Sekaran, V. Narayanan, and A. Stephen, Enhanced photocatalytic activity of $\mathrm{ZnO} / \mathrm{CuO}$ nanocomposite for the degradation of textile dye on visible light illumination, Materials Science and Engineering C, vol. 33, pp. 91-98, 2013. 